\title{
Researcher-Planner Dialogue on Environmental Justice and Its Knowledges-A Means to Encourage Social Learning Towards Sustainability
}

\author{
Aino Rekola* (D) and Riikka Paloniemi \\ Environmental Policy Center, Finnish Environment Institute (SYKE), P.O. Box 140; FIN-00251 Helsinki, Finland; \\ riikka.paloniemi@ymparisto.fi \\ * Correspondence: aino.rekola@ymparisto.fi; Tel.: +358-2952-51871
}

Received: 15 May 2018; Accepted: 23 July 2018; Published: 24 July 2018

\begin{abstract}
Societies aiming for a sustainable future need more effective and legitimate planning and decision making practices, in which various actors together find pathways towards a sustainable transition. In this paper, we approach sustainability and environmental justice as epistemological (and ontological) challenges for land-use planning, and empirically analyse how action research could support planners' social learning and planning towards fair and sustainable development. We analysed qualitatively the evolution of the researcher-planner dialogue while co-designing and developing better methods, means and practices to improve environmental justice in regional scale planning in Kymenlaakso Region, South-East Finland. We found that researcher-planner dialogue developed during cooperation. While in the beginning, social learning related to approaching environmental justice as a fair distribution of power evolved incrementally, later, when dialogue became more focused, communicative and reflective as an outcome of mutual frames and trust, learning occurred in a more transformative way. Such transformative learning concerned recognising youth as a silent group in the planning process and the means to involve their perceptions in planning. In order to support sustainability transformation in the future, we conclude that it is essential to create opportunities for such incremental and transformative social learning through innovative modes of interaction in various contexts.
\end{abstract}

Keywords: action research; environmental justice; land use planning; dialogue; science-policy interaction; sustainability; transformative learning

\section{Introduction}

Land-use planning represents the silent mainstream of sustainability transition policies and practices responsible for many strategic decisions concerning the environment. In planning as well as in other policy areas, endeavours for sustainable development embrace a strong normative dimension while calling for a transition towards a society where social and natural systems are coupled in a fair and ethically sound manner. Hence, the concept of sustainability challenges the societies committed to it to critically explore justice and other normative elements related to sustainability as well as their own ethical stances, positions and assumptions related to them.

It is sustainability that highlights planning as a space or an arena for democracy, dialogue and constructive conflict and to engender engagements [1]. The normative nature of sustainability facilitates planning with epistemological and ontological questions requiring positioning from the planners. The framework of environmental justice, including just distribution of risks and benefits [2,3] as well as procedural practices, give conceptual support for the discussion on sustainability transition in planning and planning epistemologies. Environmental justice and opportunities for it are embedded 
in planning institutions and in their interaction with the community and recognised individuals $[4,5]$. Given that the powerful in the society, such as planners and other officials, should always be cautious about defining justice and the adequate level of it [6], it becomes important that the planners have an opportunity to learn and develop competences and capabilities which the legitimate planning process requires from them [7]. In this paper, we explore empirically the dialogue between researchers and land-use planners and analyse qualitatively, how the planners' epistemological (and ontological) positioning on environmental justice develops in a real world land-use planning case and how the researcher-planner dialogue can support planners' learning in environmental justice questions central for sustainability transition.

In recent decades, the general epistemological grounds for the land-use planning have been under critical scrutiny. Positivist and techno-rational knowledge interests guiding the planning decisions have been largely criticized among planning theorists [8-12]. In the debate about alternative approaches, the Habermasian approach with an aim for the best argument, authentic dialogue and collaborative rationality $[9,13]$ as well as communicative, deliberative planning [14] has received strong support in the field. Communicative and deliberative planning poses also intricate epistemological dilemmas to the planners, who are expected to balance between multiple knowledges and knowledge frames instead of grounding their work on mere objective information or data [11,12]. Although the communicative and deliberative approaches have faced criticism on ethical grounds for ignoring societal power and strategic communication $[15,16]$, both dialogue and strategic communication may, however, be deployed in an ethical or unethical manner [17]. According to Toledano [17] key words in creating ethical process are egalitarian, transparency, honesty, openness and respect, but as she notes, more research is needed to provide good models for ethical dialogues and strategic communication.

In Finland, which we focus on, claims for extensive communication and involvement of the citizens in planning have increased during recent decades, reflecting recent epistemological debate among planning theorists [7]. Justice, transparency and openness of the land-use planning processes have been under scrutiny since the new Land Use and Building Act [18] came into force in 2000. Aiming to improve involvement is not only included in the land-use planning legislation, but it applies also to the practical level, where the interaction between the planners and the public has remarkably increased and diversified in recent decades [19]. Although in the Finnish context it has been noticed that the planners have adopted justice as a guiding principle in their work, it seems that the planners often lack methods for distributing power, safeguarding justice and, hence, tackling the epistemological challenges related to multiple knowledges during the planning process [20]. Substantial challenges related to legitimacy and effectiveness of participation have been recognised [21-23], which question experiences about the fairness and the sustainability of the existing planning processes. Thus, concrete method development is needed to support the planners' in their epistemological positioning regarding environmental justice in a sustainability transition.

Methods supporting planners' reflection and epistemological positioning [11,12] could be particularly beneficial in renewing dynamic planning circumstances, with increasing requirements for communication and reflection as well as normative responsibilities to ensure justice and sustainability, increasing uncertainty and complexity, combined with the political nature of the planning, as well as diversified modes of data, information and knowledge acknowledged to planning (including social, experimental and scientific knowledge) [1,24]. Thus, to work more effectively in such diverse circumstances with potentially emerging, diverse tensions, there is an increasing need to develop new reflective practices and means for implementing communicative and participatory planning in practice. One promising way to develop such means and practices could be providing the practitioners with tools for their epistemological positioning through social learning together with sustainability scientists.

Learning is considered to be essential for the sustainability transition [25-27]. Learning aiming for sustainability transition is, however, not just about behavioural change or changing the system $[25,26]$. Instead, it is a process which is social, critically reflexive and includes positive feedback loops among the learner, collaborators and the wider social context [25,28-31]. A social learning process aims for 
organizational change and has been recognized to have four distinct characteristics: it should consist of social action, iterative reflection, communication, and negotiation [25]. Reflection and negotiation can be considered as learning-oriented solutions to possible policy controversies or disagreements in the social learning process. Open reflection over the frames and beliefs, perceptions and appreciations underlying the controversies can provide a frame-critical rationality, which allows understanding of how one's actions contribute to a policy conflict and its resolution [32]. Problematic frames, assumptions and beliefs can even be transformed in the learning situation. This kind of transformative learning happening in a social setting requires using critically reflexive practices and emphasising the learning and teaching of skills and capabilities to reflect and transform one's existing frames [33].

In the sustainability transition, the role of science is considered to reach far beyond pure enlightenment [34], which stresses a one-way type of science-policy interaction without further dialogue. In the face of complicated and urgent environmental challenges, more critical and even "post-normal" scientific approaches have been engaged since in the field of environmental sciences $[35,36]$. Among the sustainability sciences, researchers have participated in knowledge co-production, contributed to second-order learning in niche development or boundary arrangements in the science-policy nexus, and used action research methods [37-40]. Such more interactive societal engagement of research and researcher is expected to increase the societal impact of research [41] in terms of increased security and well-being, among others benefits. However, it is not yet fully understood which contents, practices, and elements in the dialogue process between researchers and planners are particularly relevant in the context of environmental justice and sustainability [35].

With this study, we aim to advance scientific debates about knowledge claims related to environmental justice as a sustainability question in the planning context as well as on science-policy interaction within the planning practices. We approach sustainability and environmental justice as epistemological (and ontological) challenges for land-use planning and empirically analyse, by using triangulation of methods including action research, how a participatory research approach could support planners' social learning and planning towards fair and sustainable development. We discuss the opportunities and challenges concerning the dialogue between researchers and planners and their mutual social learning process. By focusing on the researcher-planner dialogue aiming for improving environmental justice in the Regional Plan in Kymenlaakso Region, in South-East Finland, we ask how and under which circumstances the researcher-planner dialogue could support transition towards fair sustainability and social learning between the researchers and planners, by answering three specific research questions:

1. How were environmental justice and the environmental justice positions, frames and conceptions of the researchers and planners articulated, approached and represented by the parties in their dialogue?

2. How did the researchers' and planners' positions, frames and conceptions for environmental justice evolve during the dialogue, and how did social learning occur?

3. Which elements were hindering, decelerating and encouraging social learning in the dialogue?

In the next section, we describe the triangulation method and the materials used in the study. We continue by presenting the results of the analysis of the discussions between the researchers and planners and the indicators for social learning on environmental justice and its epistemologies, after which we discuss them and draw conclusions.

\section{Materials and Methods}

\subsection{Triangulation: Action Research and Grounded Theory}

Our study is based on method triangulation, in which we combined case study research, action research and grounded theory. By the triangulation of methods, we aim to deliver more valid results but also to give increased scope, depth and consistency in methodological proceedings as well 
as to cope with the ethical challenges related to action research and reflective practices [31,35,42-45]. In addition, we see that the dialogue can provide opportunities for structured analysis and reflection on one's own practices, and thus improve collaboration in collective decision-making situations in the future [46].

In this paper we present a case study based on action research $[47,48]$ which we co-designed together with the Regional Council of Kymenlaakso and conducted in close cooperation with a real-life planning process in the Kymenlaakso Region (Figure 1). The researchers contacted the Regional Council in November 2016 and inquired about their interest in cooperation in a case study with a focus on environmental justice in planning. The aim of the action research was co-designed in close collaboration with the Regional Council to figure out innovative and practical means to develop, elaborate and fine-tune practices for citizen participation for a regional plan aiming to cover all regionally relevant themes by 2019 and plans for 2040. The general and shared aim of the project was to create a process of dialogue and mutual reflection between the researchers, namely us, the writers of this paper, and the planners, about procedural environmental justice. The action research approach was applied from the project planning phase in November 2016, when the thematic focus and principles for cooperation were discussed and agreed with the Regional Council of Kymenlaakso, and it lasted until April 2018, when the validation workshop was organised as a part of the action research project and a regional plan workshop was organised as a part of planning process (see Figure 2).

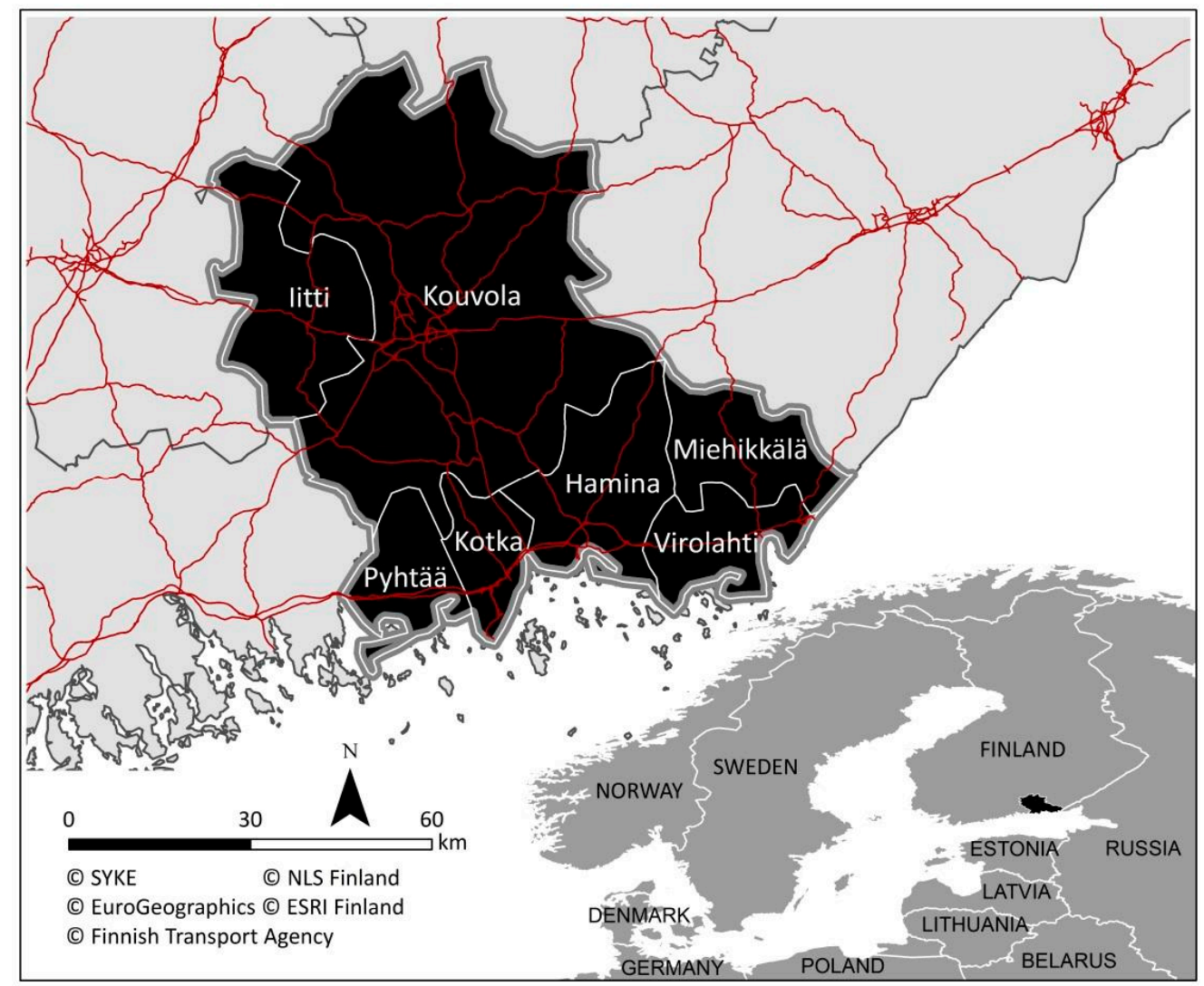

Figure 1. Kymenlaakso Region, the planning area.

Action research was chosen for the research method, for the reason that the aim of the project was not only to study but also to develop, encourage and empower critical, reflective and creative approaches to environmental justice in sustainable planning as well as positions, frames and conceptions for epistemologies and ontologies of justice which, as knowledge, are multiple and normative and accordingly seen to benefit from an interactive and reflective research approach [35]. 
The strength of the action research is in its aim of supporting social change for groups $[48,49]$. Action supports involvement in planning, learning and motivation which are observed requirements for permanent change [50]. Ideas about double loop learning, testing claims and errors and trying to validate them during the dialogue are essential features of the learning process in action research [51]. In addition, to enhance change, action research is a method for generating data [36]. Action research requires, however, critical reflection also from the researchers' side.

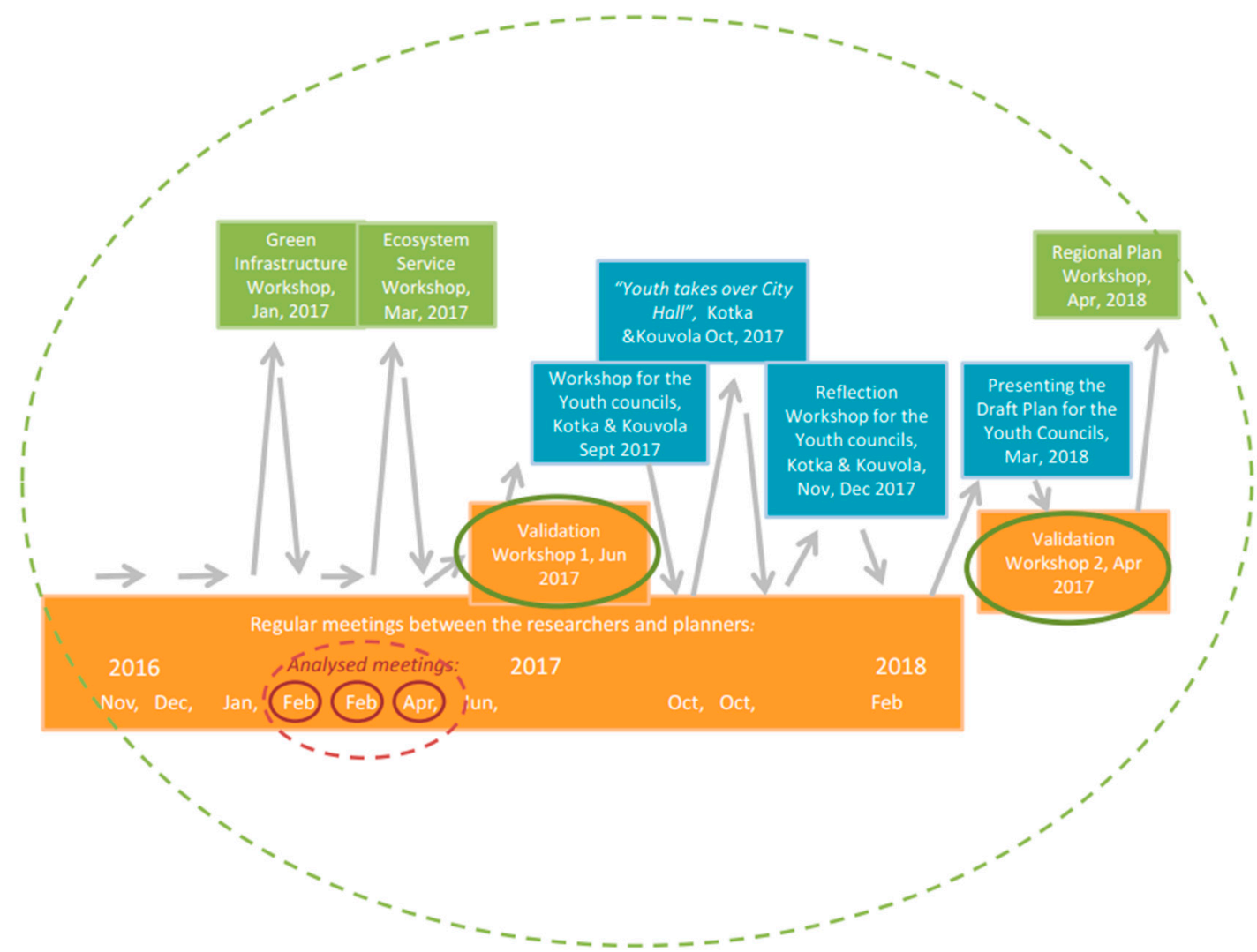

Figure 2. Research design of the study. Big green circle with dashed line represents action research process and its various events. Orange rectangle $=$ meeting between the researchers and the planners of the Regional Council; Blue rectangle = stakeholder involvement events organised with and facilitated by the researchers; Green rectangle = stakeholder involvement events organised and facilitated by the planners, observed by the researchers. Smaller red circle with dashed line represents the meetings which discussions were analysed qualitatively for this study using the grounded theory method. The two green circles indicate the validation workshops where the researchers' preliminary findings were exposed to reflective and critical dialogue in the action research setting and elaborated and validated in the researcher-planner dialogue.

Due to separate responsibilities, both parties of the dialogue had also their own intentions and aims motivating them in the action research process. We, the researchers, were interested in an empirical insight to investigate the development of a social learning process between the researchers and the planners on the concept of justice. The planners were, instead, interested in developing means and practices supporting the environmental justice perspective in designing the regional plan for the Kymenlaakso Region (Figure 1). The motivations were openly discussed in the meeting between the researchers and planners already when planning the project as well as during the action research process. Both parties were committed to their own aims and to respect each other's aims in the process.

A researcher speaking for fair planning in an action research setting is holding a position of an advocate with moral claims in at least in two senses. Firstly, the environmental justice paradigm is 
a normative approach, while a claim for an equal distribution of power and environmental burdens and benefits is a political one by nature. In our case study, environmental justice was chosen for the research topic together. The planners were willing to develop procedural justice in their planning and the researchers were willing to study this development process. In our research team there were discussions during the action research process, whether we should intervene also to questions on distributional justice in the planning which had been the case in our previous projects. As a resolution, we decided in February 2017 not to take any stances regarding distributive justice and to respect this original aim of the study. Secondly, action research puts the researcher in a position where she is required to critically reflect also on one's own ethical stances, values, norms and attitudes during the research process $[31,35,43,44]$. We were able to elude many of the dilemmas recognised in the previous action research studies [43] due to (1) a relatively small research team (5 researchers actively participating the action research) where the action research objectives and principles were constantly reflected; (2) critical reflection on the frames concerning environmental justice and its distributive and procedural aspects in the research team; and (3) the validation workshops which made visible the difference between the action research method and the more instrumental and evaluative analysis made by the researchers and which opened the initial results for a critical reflection for the planners.

\subsection{Material}

The primary material for this study was gathered as a part of a series on interactive meetings and workshops. Two to five researchers and one to five planners attended each meeting or workshop.

As primary data, we used transcribed recordings made in the monthly project meetings between us-the researchers-and the planners of the Regional Council as well as in the workshops related to the Regional Plan process. The recorded and transcribed meeting discussions which were used as a material for this study were gathered in three researcher-planner "monthly meetings" out of a total of 10 "monthly meetings" in November 2016 and February 2018 (Figure 2). "Monthly meetings" were organised as skype meetings. The lengths of the discussions varied from $33 \mathrm{~min}$ to $1 \mathrm{~h} 51 \mathrm{~min}$. The most typical length was around one hour. In the meeting the planners reflected the ongoing planning process and the researchers.

We also facilitated two validation workshops for the planners which were organised as approximately two-hour long face-to-face meetings (in June 2017 and April 2018). In the validation workshops, we facilitated the discussion and tested our initial findings. These discussions were also transcribed and the latter was used as material in the analysis for this study.

In addition, together with the planners, we also facilitated four workshops for Youth Councils and two events held at the Youth Takes over City Hall fairs. In addition, we observed the dialogue of the planners and the stakeholders in three official stakeholder involvement workshops related to the Regional Plan. These workshops were organised by the planners and facilitated by consultants, except the last workshop, which was also facilitated by the planners. The material from the workshops for the Youth Councils and the official stakeholder involvement workshops related to the Regional Plan will be analysed in another study.

During the action research process, we wrote a project diary reflecting the development of the planning process and the discussions with the Regional Council. This collective diary of researchers concluded observations and reflected the content of the events and learning outcomes (recognised and potential). It is worth mentioning that the diary represents a secondary type of data as it includes our reflections based on our previous understandings on justice as a theoretical concept and our interpretations of the events and learning (recognised and potential) during and between them.

\subsection{Analytical Steps}

The results which we present in this paper are based on the material produced during the action research process. Our analysis was threefold and it encompassed both primary and secondary types of empirical data consisting of material from the meetings and validation workshops of researchers, 
planners and other stakeholders and the collective diary of researchers reflecting these events and learning (recognised and potential) outcomes. During the analysis, we incorporated both reflective analysis and reflexive questioning for the material gathered in a process of reflexive interaction [31].

First, in order to focus our analysis on the meetings relevant from the perspective of social learning for environmental justice and sustainability, we analysed research diaries. Based on the diary notes, we aimed to recognise justice-related proceedings by which we mean justice-related discourses shared by the researchers and the planners in the dialogue and which turned into an activity addressing justice during the Kymenlaakso Regional Plan process or represented a new kind of epistemological or ontological positioning by the planners to the justice-related issue. In the analysis, we explored retrospectively our interpretations of occasions which were perceived to generate substantial change in understanding or in approaching environmental justice in the planning process. We paid particular attention to the varying aspects of environmental justice, including fair processes and outcomes, power distribution, and the recognition of various actors and actor groups (see [3,19]).

The second step of the analysis was to analyse the dialogue between the researchers and planners around the occasions of the recognised proceedings. We analysed retrospectively the discussions between the researchers and planners inductively and by using the grounded theory method [52]. The aim was to analyse, how researchers and planners spoke about justice and how they justified their justiceor process-related claims, whether and how the learning process was actually occurring and emerging, and finally, how the roles of researchers representing scientific understanding on justice and the planners representing advocacy and reclaiming of justice developed.

Then, we started the analysis of the meetings' discussions by coding it openly and inductively. The initial coding process resulted in a set of codes showing the development as the material was coded over time but provided a rather unclear picture of the whole due to a large amount of codes. The coding was repeated anew and developed from the initial open coding towards an integrated coding by using the constant comparative method (see [52]). In the end, the codes and the integrated codes were comprehensively grounded on the theoretical frameworks interpreted to resonate with the relevant elements of the discussion between the researchers and planners (Table 1).

Thirdly, we turned to the planners' side to test and validate our initial findings especially regarding the justice-related proceedings. At this stage we returned to the action research setting and exposed our findings to critical reflection in the researcher-planner dialogue. In both of the validation workshops we asked the planners to assess the planning process "ex post" and produce a timeline of the planning process highlighting their experiences about developments and successes, failures and setbacks related to environmental justice. We presented our initial findings only after the planners had drawn their timeline and discussed the similarities and differences of our findings openly with the planners. The validation workshops turned out to have a significant role both in the analysis of the social learning as well as in the action research process and reflection. In the second validation workshop the planners rejected one of the findings, which we thought to have been a significant justice-related proceeding. After the planners' comments and thoughts regarding our findings, we considered that one of the findings which we had assumed represent a justice related proceeding in the process was falsely based on a performative statement rather than a shared discourse enabling further learning [53,54]. This justice-related proceeding, which was not recognised by the planners, was since left out of the further analysis.

Our three-fold analysis—one over time, another on the themes and discourses, and the third validating the initial findings-enables us to draw conclusions on the substantial progress and proceedings in the dialogue and on the elements that were hindering, decelerating and encouraging learning in the process.

\section{Results}

In the analysis of our research diaries and researchers' reflections on the dialogue with the planners, we recognised two proceedings indicating learning and evolving epistemological positioning 
related to environmental justice during the action research process. The first proceeding was related to mutual understanding about power distribution as an objective for a just planning process, and second was related to recognition of the youth as a silent group in the planning and decision making processes in the region. Identification of these two proceeding guided us to focus our intensive analysis on the three meetings (Figure 2).

In the grounded theory analysis of our primary research material, the discussions, we observed that the justice discourses present in the dialogue were not only about just power distribution in the process and recognition of stakeholders. Instead, there were multiple elements relevant to the environmental justice present in the dialogue between the researchers and planners (Table 1). We recognised that regarding planning, both procedural and distributive aspects were covered. In addition, stakeholder involvement was discussed from the perspective of general objectives of the involvement and aims of the stakeholder involvement: whether the aim of the involvement is to distribute power between stakeholders or gather knowledge from the stakeholders (see [55]). Similarly, methods used in the stakeholder involvement activities were found to contrast with free dialogue and active facilitation.

In addition, the researchers and planners were observed to approach knowledge from different perspectives. On one hand, knowledge was discussed as something which could be framed in/for the planning process, reflecting the ideas of Schön [56] and Puustinen [57]. On the other hand, knowledge was seen rather as information to be produced/filtered in/from the process.

Moreover, the researchers and planners gave a host of positions for the various stakeholders in the planning process. One position given for the stakeholders in dialogue called notions of Fraser [58] and Foucault [59] by emphasising the voices of stakeholders (and the silence of them), as well as discourses and power regarding stakeholder involvement. In addition, attention was also paid to various habitus [60] of stakeholders by describing various characteristics and capacities relevant for participating in the planning processes.

Planners' positions, in turn, reflected the findings of Puustinen [57]. In the reflective position, planners were reflecting their own renewing expert positions and planning processes creatively; but the discourses were also referring to the traditional professionality of planners by referring to law and its obedience, by supporting or claiming it.

Finally, researchers were also taking various positions in the dialogue reflecting the Habermasian understanding of different knowledge interests and varying from a more communicative position, where open questions were presented and even difficult theoretical concepts were described, towards a more strategic position, where more direct and concrete advice was given to planners (see [61]).

Table 1. Environmental justice and action positions of various actors. Themes discussed in the meetings of researchers and planners.

\begin{tabular}{|c|}
\hline Planning \\
\hline $\begin{array}{l}\text { Process } \\
\text { - } \quad \text { Phases of the planning process } \\
\text { - } \quad \text { Legality and legitimacy of the process }\end{array}$ \\
\hline $\begin{array}{l}\text { Outcome } \\
\text { - } \quad \text { Regional land use plan } \\
\text { - } \quad \text { Plan symbols } \\
\text { - } \quad \text { Distribution of environmental setbacks and benefits }\end{array}$ \\
\hline
\end{tabular}


Table 1. Cont

\section{Stakeholder involvement}

\section{Objective for the stakeholder involvement}

- $\quad$ Basic principles related to stakeholder involvement

- Planning of the stakeholder involvement methods according to the knowledge relevant to the planning

- Communicating the objective for stakeholder involvement

- $\quad$ Role and phase of stakeholder involvement in the process

\section{Technical practices of stakeholder involvement and their implementation}

- Variety of methods and discussion on how to use them

- Group formation in the workshops

- Timing of stakeholder involvement

- Distributing the results of stakeholder involvement

\section{The objective of stakeholder involvement see [56] \\ Power distribution \\ - Equal balance of stakeholders and their voices and ensuring it \\ - Distribution of professional power \\ - Methods distributing voices and power}

\section{Information gathering/Consultation/Informing}

- Information gathering, consultation or information sharing as an objective for the stakeholders' involvement

- Methods and procedures aiming for effective knowledge gathering

\section{The method of stakeholder involvement}

\section{Facilitation}

- Facilitation as a stakeholder involvement method

- Facilitation process

- Power distribution by facilitation

- Active support for the dialogue between stakeholders

- Open interpretation of viewpoints of the stakeholders

- $\quad$ Strengths of facilitation

\section{Free dialogue}

- Free dialogue as a stakeholder involvement method

- $\quad$ Strengths and weaknesses of free dialogue

\section{Approaching knowledge in the involvement process}

\section{Framing knowledge in/for the process see [56,57]}

- Reflecting the knowledge production system from the viewpoint of the stakeholders

- Designing the involvement methods by taking into account the stakeholders' perspective of knowledge

- Taking into account the stakeholders perspective of knowledge when speaking about knowledge

\section{Producing/filtering information in/of the process}

- Producing information for the purposes of the planning

- Defining the quality and nature of the information necessary for the planning

- Local knowledge and knowledge produced by the stakeholders

- Verification of the existing data 
Table 1. Cont.

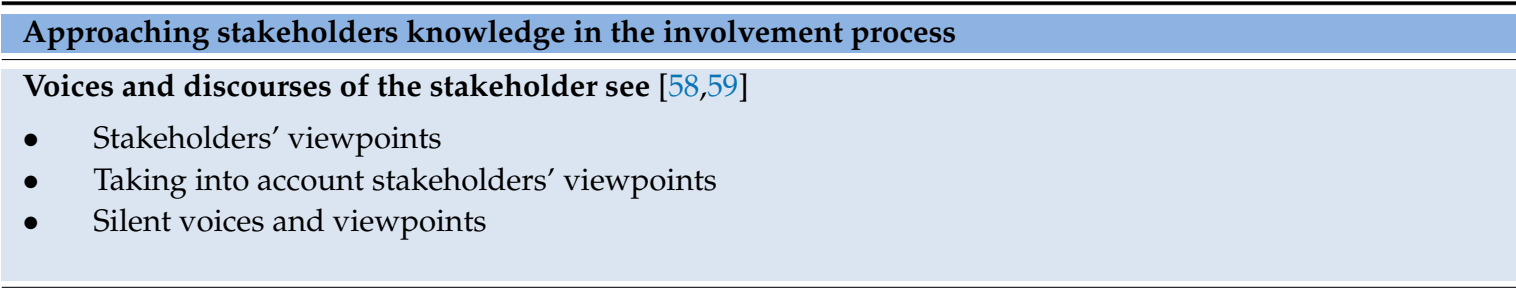

Habitus of the stakeholder see [60]

- Attitudes, capacities or characteristics of the stakeholders

Approaching the role of planners in the involvement process
Reflectivity
$\begin{aligned} & \text { - Planner reflecting his/her position, activity or jurisdiction } \\ & \text { - Planner taking into account stakeholders' viewpoints } \\ & \text { - Planner talking reflectively on the planning process or developing of it }\end{aligned}$

\section{Traditional professionality or claiming of it}

- Planner defending his/her standpoint, viewpoint and/or position

- Planner referring to the law and law obedience

\section{Researchers position in the dialogue see [61]}

\section{Communicative}

- Researchers explaining their perspectives and perceptions

- $\quad$ Researchers referring to research and research results

- Researcher referring to previous experience

- Researchers asking questions supporting the planners' reflectivity

\section{Strategic}

- Researchers giving advice

- Researchers aiming for a certain aim

In Figure 3, we conclude, how the content of dialogue regarding various elements relevant for procedural environmental justice evolved during the three meetings of planners and researchers discussed by a planner or a researcher, and in Figure 4, we present how the approaches related to environmental justice and actors' positions and discourses evolved during the three meetings of planners and researchers. The progress of the content of the dialogue will be explained more in the next chapter.

In the dialogue between the researchers and planners in three meetings, there was essential progression on how the parties were approaching procedural environmental justice and how the progression occurred. On one hand, during the three meetings, learning to understand the impacts of different methodological choices to justice as power distribution occurred rather slowly and incrementally. On the other hand, in the third meeting, more transformative learning occurred, when the planners recognised that one silent group, namely the youth, was not involved in practice in the planning process. It was also recognised that the involvement of this specific group required new, more informal involvement methods, and even a new, innovative approach which had not been previously used by the planners. 


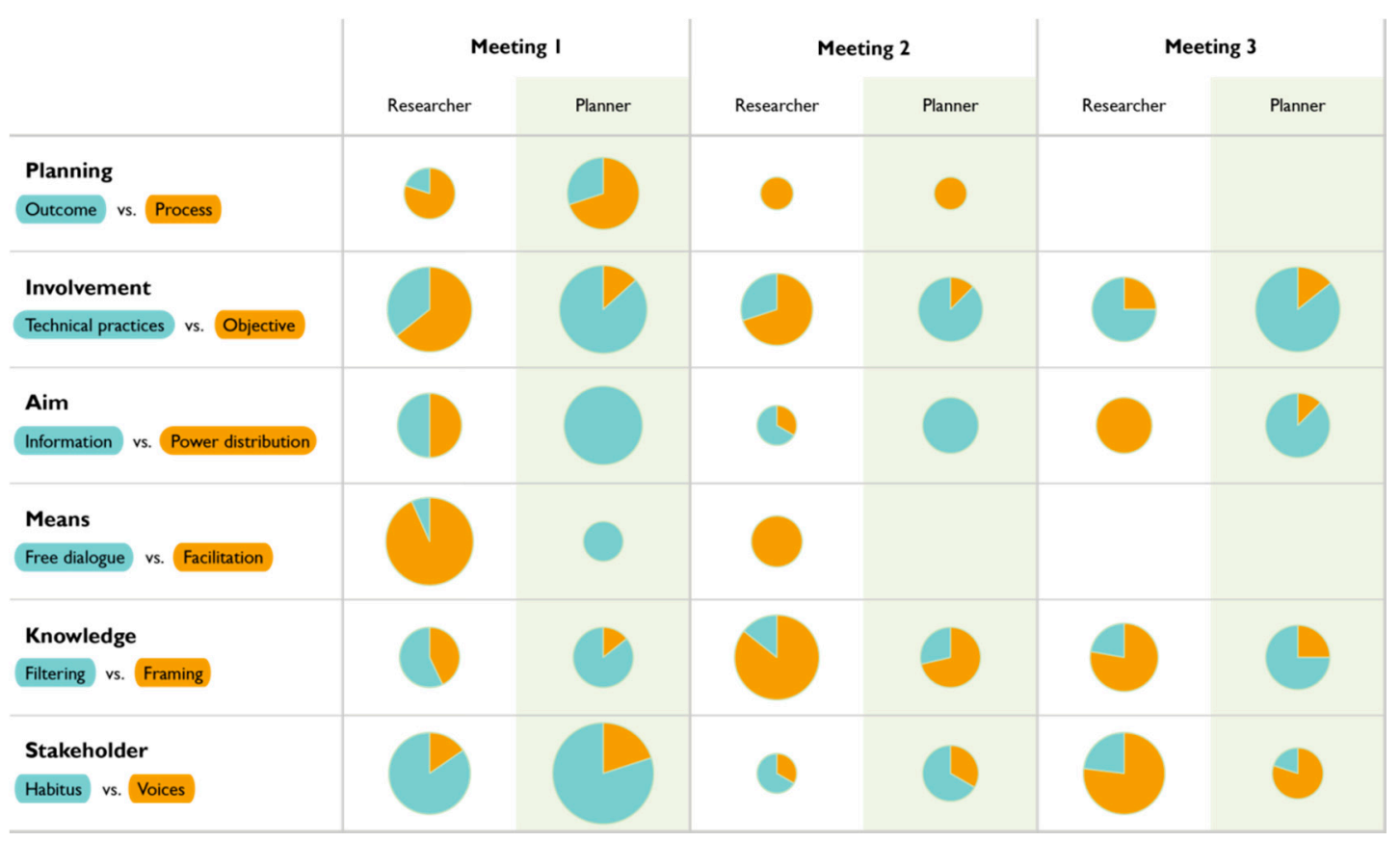

Figure 3. Evolving themes regarding aims, means and foci of stakeholder involvement and knowledge in regional scale planning. Themes discussed during the analysed researcher-planner dialogue.

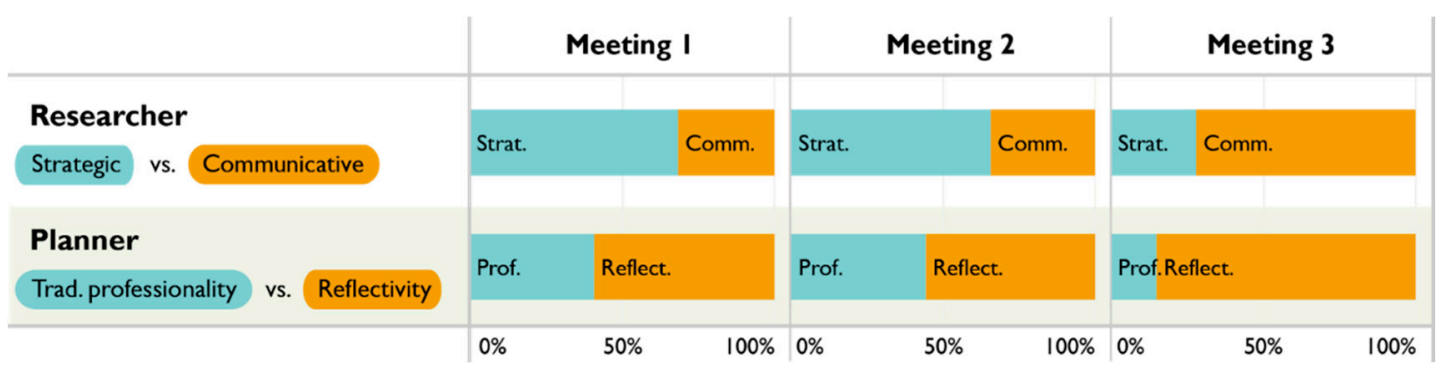

Figure 4. Towards communicativeness and reflectivity. Evolving approaches in researcher-planner dialogue regarding stakeholder involvement in regional-scale planning.

However, we observed that the learning processes during the researchers-planners dialogue were not linear. Instead, we recognised different kinds of hindering, decelerating and encouraging elements that were present in the dialogue in all meetings.

\subsection{Elements Hindering Social Learning}

The dialogue of the first two meetings did not lead to a specific proceeding or substantial learning, as also acknowledged by the planners in the discussion in the validation workshop. The first two meetings differed from the third meeting in three respects that we interpreted to have hindered mutual learning during the dialogue.

Firstly, in the two first meetings, the content and messages of the arguments presented by both the researchers and planners were dispersed and concerned a wide range of topics (Figure 3). The parties were also arguing for their own agendas with a focus on different facts and not finding common ground by reflection in order to develop the process or circumstances for mutual learning and generating trust. In the first meeting, the researchers spoke actively about the objective for stakeholder involvement and power distribution, whereas the planners highlighted technical practicalities and formalities of the stakeholder involvement and how to carry them out. The planners also drew attention to knowledge-gathering, consultation and informing as the objective for stakeholder involvement. 
On the other hand, the parties were interpreting the same situation in different ways. This was most visible when the parties were discussing the method for stakeholder involvement. The researchers spoke up for active facilitation as a technique for power distribution between the stakeholders. Instead, the planners were arguing for free dialogue as an appropriate method for stakeholder involvement (Figure 3). The following citation from the first meeting illustrates the dialogue where the researchers were arguing for active facilitation (and against free dialogue) and the planner was defending the chosen method by describing the technical practicalities of it and reasoning the failure by referring to the actions of the stakeholders.

R: Did you talk with the consultant—as you just said that you did not want to lead the discussion to any direction - [... ] about free dialogue, because there are in a way strengths and weaknesses—-that the discussion follows the track like it follows. But in a way it is-to some point-its weakness. Did you talk with the consultant for choosing this method?

P: Well, of course the discussion was led with the question template, which was there. They should have discussed the certain questions and answers which were on the template. That was the one which led the discussion automatically. And the task for the facilitator was to make sure that all the questions were answered. Or at least almost all.

$R:$ But there were no facilitators in the groups.

(M1)

Secondly, in the two first meetings the researchers had ambiguous expectations towards the planners and the planning process. Researchers presented several notions including direct suggestions for the planners, guiding them and giving them advice on how to implement the stakeholders' involvement in a fair manner (Figure 3). These were interpreted to represent strategic argumentation (Figure 4). Looking across the researchers' strategic arguments, we discovered that they were inconsistent and aiming for different goals. Especially in the first meeting, the strategic arguments about knowledge were unfocused and even contradictory to some point (Figure 3). Comments regarding the methods of the green infrastructure and ecosystem service reports, the analyses behind them and stakeholder involvement as a knowledge production or filtration process were giving support for a techno-rational planning ideal. Instead, the comments about developing the methods for stakeholder involvement and planning as a knowledge-framing process were aiming for developing power distribution and justice in the process. In addition, in the first meeting the researchers' communicative arguments-aiming for better understanding-were not supporting their strategic arguments excluding their arguments on power distribution and active facilitation. Moreover, the researchers were even questioning each other's viewpoints. By the third meeting, the researchers' discourses on the knowledge had become focused; as early as the second meeting, the researchers' notions about knowledge were more balanced and more focused on the knowledge framing instead of information production or filtration (Figure 3).

Thirdly, there was no open reflection on the concept of justice between the parties until the third meeting. Even though in the beginning of the action research process, it was agreed that the dialogue will focus on procedural aspects of justice; in the first meeting, both researchers and planners voiced a few notions about distributional justice. They were speaking about the planning solutions and the plan symbols.

Most notably, there was no open discussion on how justice, the concept in focus of the dialogue, was understood and perceived. Consequently, there was no mutual understanding or acceptance on the general grounds for developing justice in the first two meetings.

Finally, in the validation workshop, we recognised that the organisational hierarchy is also one of the potentially hindering elements with regard to social learning during the researcher-planner dialogue. In the validation workshop, there were more planners in place than usually in the monthly meetings discussing the process and the dialogue between the researchers and planners. The planners were speaking reflectively throughout the discussion, but the roles and power positions, which the 
planners had inside their organisation, were visible in the discussion setting in a manner which we had not previously observed in our discussions with two or three younger planners primarily working with us.

\subsection{Elements Encouraging Social Learning}

Unlike the first two meetings, the dialogue in the third meeting led to fruitful cooperation and a substantial proceeding with regard to justice improvement and in learning between the researchers and planners. After the meeting, the researchers and planners started to cooperate to involve youth in the planning process. We found out that the third meeting differed in five respects from the two previous ones: the discussion and argumentation of both parties were more focused (Figure 3), the researches were presenting more communicative than strategic arguments (Figure 4), the planners were showing reflectivity (Figure 4), the researchers and planners had an open discussion on justice and knowledge, and they got to know each other better.

Compared to the two previous meetings, in the third meeting the researchers and planners engaged in more discussion about the objective for stakeholder involvement, power distribution and voices of the stakeholders. The researchers' discourses were more focused on the topics reflecting the current understanding of procedural justice within academia. Moreover, in the third meeting the researchers' arguments were in general more communicative than strategic (Figure 4) and the strategic arguments were also relying on the message of the communicative arguments.

The planners, instead, were showing reflectivity in a manner which stood out from the two previous meetings (Figure 4). The planners' general discourse also had new elements in the third meeting like the comments concerning the voices of the stakeholders (Figure 3). The following citation illustrates the planners' reflectivity.

R: Often in those involvement processes, people feel that they only had an opportunity to be a "rubber stamp", which probably relates to an aspect of the discussion on procedural justice, that if you get an opportunity to define what the discussion is about, then it on the one hand commits the stakeholders to the decision, but on the other hand it also helps to better define what the discussion is about. [presents an example from climate policy].

P: And I find it very important that, if we decide to involve a group, then [ . . ] we need to also commit ourselves to taking their viewpoints into account.

In the third meeting, the researchers and planners had a comprehensive discussion about the concept of justice and their perception on it. A planner opened the discussion by asking researchers to explain the concept. During the conversation, both researchers and planners took stances and showed acceptance towards each other's justice perceptions by presenting short comments.

P: Could you please open the concept of procedural justice for me? What does it mean?

R: Okay, good. [Explains the term in Finnish.] [It is] about practices, methods and their implementation and about putting them into practice in a way which will happen fairly. The justice principles are such as people having an opportunity to represent themselves, participation implemented in a way, which takes into account all essential aspects. [... [ [P]rocedural justice is [also about] decisions as publicly available, an opportunity to make an appeal about them. [ ... ] [I]n this kind of planning process in which we analyse justice, [the perspectives on it], who participates, how people can participate and what kind of viewpoints it is possible to have on board and which viewpoints are represented [are important]. [ ... ]

P: Yes.

P2: [ ... ] We often quote a citation: "even a worse result can be accepted if the process has been legitimate".

P: Okay. I have been almost on the right track. 
$[\ldots]$

$R$ : Could you tell, what do you think -what are the most relevant points in procedural justice? How do you approach it?

P: Well, we were discussing it earlier: how we could get as many viewpoints of the different interest positions as possible evenly heard in this topic, including, from the perspective of sustainability. I find it important that the solutions would be evenly divided between social and economic perspectives.

R: Sounds good.

[...]

P: And particularly different kinds of practices and methods for stakeholder involvement. We should find those best ones and those which are also feasible for us in terms of our resources.

\subsection{Elements Decelerating Social Learning}

In all analysed meetings, the researchers were speaking both communicatively-aiming for a shared understanding; and strategically-aiming for a specific goal (Figure 4). However, strategic speaking had a different impact at different stages of the dialogue. We see that there were two reasons explaining this: the (in)consistency of the messages behind the strategic and communicative arguments as well as mutual understanding on and acceptance of the goal defended by strategic argumentation.

In the earlier stages of the discussions, the researchers presented strong, strategic arguments for active facilitation as a proper method for power distribution that ensured justice in the planning process (Figure 3). As described above, there was, however, no mutual understanding of the concept of justice. Neither was the idea of justice as power distribution openly reflected or accepted as a mutually understood aim for justice. In the discussions, the researchers were speaking for active facilitation, because they saw it as a method for reclaiming more justice in the process. The following citation shows how the planners rejected the researchers' comment which showed rather direct criticism towards the planners' actions while aiming to claim for a better method.

$R$ : I was wondering whose task it is to lead the discussion to the objective. I see that it is wrong to give the task to the stakeholders. [... ]

P2: Please do not stick to that. We have not given this task to the stakeholders. The template was there and the task of each of us planners and of the consultant was to communicate: "Hey, we should do these tasks". This has failed in [one sub-group]. But it was not the intention that the stakeholders lead the discussion.

P1: I had [another sub-group] and it was fine as well.

In the situation, the researchers started to speak communicatively. Questions that were rhetorically communicative, but had a strategic purpose behind them, did not support the dialogue and lead the discussion towards mutual understanding on the idea behind claiming for facilitation.

$R:$ [ . . . Can you see any solutions to the situation in which they [one stakeholder group] have this kind of position? [ ... ] How could you have broken the positions?

P2: Well. The initial attitude is already this. And the first and foremost thing would be to have impact on this attitudinal environment. [ ... ] Maybe the way one could have an impact on it would be to think about how the voice of the other party could get heard better. [ ... ]

$R$ : What kind of solutions would you see here?

$[\ldots]$

P1: Well, probably the events could be held in the evening or we could send out the report for comments before, or - that is to say -after the report is ready. Then they can have a say this way. [ ... ] 
Instead, deliberately communicative arguments that meticulously justify the claims for facilitation were observed to trigger reflectivity among the planners. However, it turned out that the circumstances in the first two meetings were not favourable for substantial proceedings in the learning process.

$R:[\ldots]$ I was trying to say that there are themes which are relevant especially for the regional planning. And [I mean] to facilitate the discussion towards these which, in a way, could bring out the Habermasian argument about [ ... ] what kind of knowledge the regional plan could synthesise on a planning level, and facilitate the discussion towards that. Then they [the involved stakeholders] could discuss more evenly.

P: Yes right, that could be a solution.

\section{R: Well, which themes would see}

P: But when you said that they already pointed out those important sites in the [third sub-group], they particularly pointed out those sites which were not included in the results of the analysis. [...] I mean that, it was important that they pointed them out. It is information for us, that the analysis lacks something which could highlight those important sites.

However, in the third meeting, the researchers' strategic arguments worked differently. In the meeting, the strategic arguments were in general in line with the researchers' communicative arguments, and they were opening a new conflict-free horizon for co-developing new means and practices to improve environmental justice. In addition, they resulted in planner reflectivity, unlike in the previous meetings.

\section{Discussion}

In this paper, we have described an action research process in the regional scale planning reflecting how social learning may occur as a part of researcher-planner dialogue, and how the content, practices, and elements in the dialogue process may be of particular relevance in improving environmental justice and sustainability and in tackling the epistemological challenges related to them in the planning context.

We found out that the social learning occurred in the process between the researchers and planners in a non-linear way, beginning from incremental steps. In the beginning of the dialogue, there was (too) strategic communication combined with inconsistent discussion and persistent attempts to reframe environmental justice as a fair distribution of power and its implications for stakeholder involvement. The learning process was slow and did not turn into a substantial change in interpretation of the planning process, or developing of action research process. However, only after more explicit communication concerning the most relevant concepts regarding environmental justice and their implications for regional scale planning, prerequisites for mutual understanding and communicative and reflective, more authentic dialogue $[13,53]$ were to evolve, which, in turn, was able to encourage a more transformative type of learning in terms of legitimate and effective strategic communication (Figure 5).

There are several interpretations why framing environmental justice, in the beginning of action research process, as a fair distribution of power resulted in incremental, instead of transformative social learning transforming problematic frames, assumptions and beliefs on aims, means and foci of stakeholder involvement and on multiple knowledges operationalized as indicators for learning on environmental justice [33]. A major challenge hindering transformative learning was the way that the researchers approached the complex theme of environmental justice in the first meetings. In the first two meetings, the various aspects of environmental justice were presented rather unsystematically, covering both procedural and distributive aspects. However, while the process evolved, the researchers' reflections on the various aspects of environmental justice focused remarkably, while the emphasis was turned more transparently only towards procedural aspects, following the explicit wishes of planners. This notion indicates the need for ethical dialogue and strategic communication in the 
researcher-planner dialogue, a challenge raised also by Toledano [17] as well as the researchers' ability to support learning (by teaching) of skills and capabilities to reflect and transform the existing frames on power distribution [33].

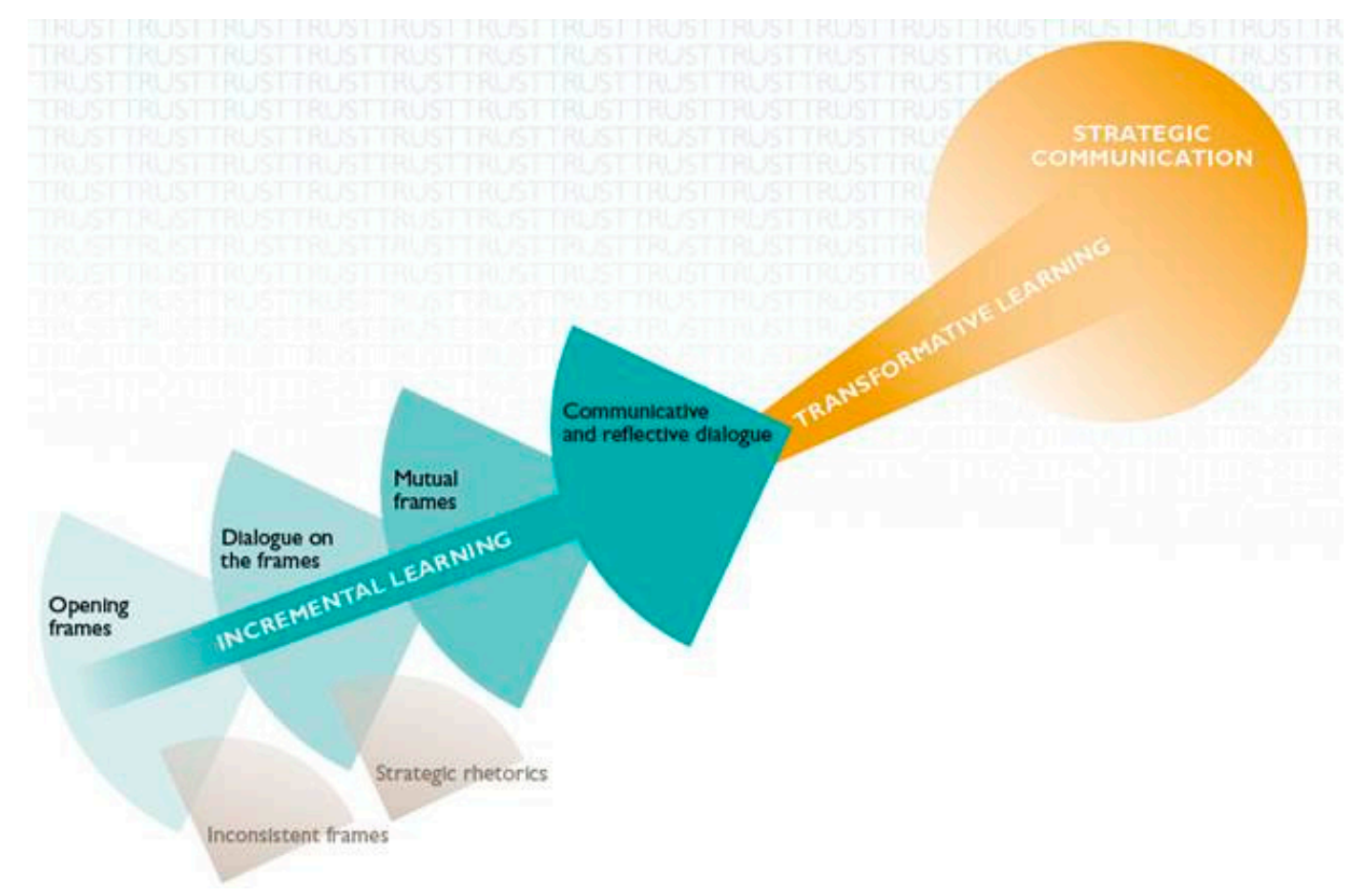

Figure 5. Social learning and its limits in researcher-planner dialogue. Inconsistent frames and strategic rhetoric in the early phases of researcher-planner dialogue were hindering social learning, while opening of various frames and dialogue based on them evolved to mutual understanding regarding the frames, encountering incremental learning. As an outcome of the process evolved trust, understanding and other prerequisites to communicative and reflective dialogue, which in turn, was a prerequisite for transformative learning towards evolved more legitimate and effective strategic communication.

There were also certain aspects in the planners' position, foci and action that hindered transformative social learning in the first meeting: by paying attention to rather technical aspects of public participation such as knowledge gathering, modes of consultation and informing as the objective for the stakeholder involvement, the planners were speaking a different language than the researchers, framing the usability and feasibility of various involvement methods from different angles than the researcher (based on the law). Combined with the notion, described above, of how researchers' communicated poorly, using the rather unsystematic and strategical framings, these various aspects decreased the openness for new interpretations to improve sustainability and environmental justice in particular. Finally, it was not surprising that the planners were not satisfied with the outcome of the first meetings, indicating the limits of too strategic one-way communication not meeting the criteria of reflective research $[31,32,35,43,44]$.

However, during the action research process more transformative social learning was also experienced and encountered in innovative co-development of environmental justice in planning and cooperation between the researchers and planners. As already mentioned, such a more transformative social learning occurred as an outcome of remarkably improved communication. Thus, a question for developing science-policy communication in the future is how to encourage communicativeness for those involved in such processes? 
In our action research project transformative learning occurred due to the new communication skills and competence of both planners and researchers to approach and communicate about epistemological (and ontological) dilemmas related to the question of environmental justice and its knowledges more thoroughly and systematically, the competence which developed during the dialogue. In the beginning of the dialogue, there were controversies between the parties that could not be resolved by appealing to facts. The researchers and planners focused on different facts and framed the same facts differently. Thus, our findings support the previous findings that too fixed, non-mutual frame setting and imposing them too simply may hinder communicative and reflective dialogue, and accordingly transformative learning for sustainability [31-33,35,43,44]. In other words, we see that researchers' strategic speaking on power distribution paved the way for mutual understanding of certain core concepts of environmental justice, which, in turn, had a weakening impact on the communication. However, in the third meeting the communication process was sufficiently mature to evolve towards co-developing interactive and innovative participation methods for youth based on more authentic dialogue. Following the conceptualization of Vare and Scott [26], during the action research process the communicative approach seems to have changed from learning for sustainability (i.e., from rather technical aspects of involvement) towards learning as sustainability (i.e., towards approaching involvement more as a process encouraged by the dialogue between the researchers and planners in an open mood).

Also trust building between the researchers and planners was an essential element when social learning developed towards more collaborative and reflective process (c.f. [62-64]). We recognised that, on one hand, the non-disclosed agendas (of any involved actors) used in the beginning of the process were not able to generate trust, and on the other hand, that in building mutual understanding and trust, enough time and cooperation were needed. In our case, regular meeting together and piloting of new means and practices (even though not all of them were working immediately), were relevant steps on the non-linear learning process, which was simultaneously building trust and shared ontological assumptions, encountered in taking risks by widening the involvement efforts to new audience, youth, with new uncertain methods. Thus, our experiences support Hoffman's [63] conclusion that trust is linked to a willingness to take risks on the behaviour of others, while it strengthens the belief that potential trustees will 'do what is right'.

Reflecting the critics that trust and dialogue based approaches may ignore societal power and strategic communication $[15,16]$, we believe that it is worth discussing briefly the context where the new approach and methods were tested. The major transformative learning step which occurred, was concerning involvement of the youth, a previously silent, but also rather powerless social group in the regional planning context. Their involvement reflects recognition, a well-known criteria for environmental justice. But in terms of reclaiming justice, the process should also meet other criteria more closely related to multiple knowledges, values and power and, hence, requiring the planners to face and argue about the epistemologies, ontologies and norms in, during and behind the planning process. Youth represents a conflict-free zone of public engagement and therefore it can be considered as a minimum-risk start for developing means for environmental justice. However, the epistemological and ontological dilemmas related to environmental justice and thus sustainability transition remain unsolved in the planning process. The question for future research is, are there scalability and opportunities for widening communicative and trust-based science-policy dialogue or co-development towards the more power-laden arenas of the planning process?

The scalability of widening communicative and trust-based social learning depends, besides public efforts, on what happens within the organisation itself. Thus, it is worth thinking how social learning between the researchers and planners transfers into learning within the organisation. Social learning regarding justice as power distribution was experienced by those actors thoroughly involved in the action research process, and their experiences do not necessarily and automatically widen to the organisational culture or routines of other employees. Instead, such develop needs even further efforts and development $[62,65]$. Thus, future research should empirically analyse how 
organisational power that may decrease or increase the potential impact of action research could be better taken into account in planning the circumstances and context for dialogue. Moreover, in future action- and practice-oriented studies, it is essential to pay more attention to integrating other personnel, particularly those having strategic power, into the dialogue process to ensure more general organisational learning. This leads to interesting arenas for future research: whether and how there are defensive routines [65] or boundary arrangements [66] within the scientific community or in the planning organisations that are limiting social learning between the researchers and planners? How the action research setting could be developed to support transformative learning in the planning processes in a way that overcomes organisational hierarchies and what kinds of capabilities researchers should develop in order to be more effective in reflective practices aiming for learning among policy practitioners?

\section{Conclusions}

In this paper, we describe the anatomy of one social learning process analysed by using a triangulation of methods including participatory methods. This learning process from the planning context highlights the opportunities and challenges in the dialogue between researchers and planners on developing environmental justice which, as knowledge, poses epistemological dilemmas which the planners are not able to solve on mere objective grounds. In this study, we explored the capacity of the action research approach to simultaneously foster an active dialogue between researchers and planners, produce development in integrating environmental justice perspective in the planning process, and, thus, support the work of the planners in their navigation across epistemological dilemmas related to conflicting interests and pressures from the stakeholders' side. We found out that there was a non-linear social learning process between the researchers and the planners. On the one hand, there was incremental learning regarding approaching environmental justice as fair distribution of power, and a more transformative-type of learning regarding recognising youth as a silent group in the planning process. We also found that researcher-planner dialogue developed during cooperation; and dialogue became more focused, communicative and reflective as an outcome of mutual frames and shared trust. In order to support sustainability transformation in the future, it is essential to create opportunities for incremental and transformative social learning through innovative modes of interaction in various contexts and recognising also intricate power relations in the process.

Author Contributions: Conceptualization, A.R. and R.P.; Methodology, A.R. and R.P.; Validation, A.R. and R.P.; Formal Analysis, A.R. and R.P.; Investigation, A.R. and R.P.; Data Curation, A.R. and R.P.; Writing-Original Draft Preparation, A.R. and R.P.; Writing-Review and Editing, A.R. and R.P.; Visualization, R.P. and A.R.; Project Administration, R.P.; Funding Acquisition, R.P. and A.R.

Funding: This research was funded by the Academy of Finland, grant number 304515.

Acknowledgments: We would like to thank planners of the Regional Council of Kymenlaakso for their commitment and cooperation in our BRO action research project, and researchers Anna Pulkka, Sanna-Riikka Saarela, Arto Viinikka, Leena Kopperoinen ja Linda Karjalainen for their valuable contribution during various phases of action research, and A. Viinikka also for producing the map, as well as Matti Lindholm and Satu Turtiainen for the design of the figures, Kaisa Raitio for discussion on transformative learning, Minna Kaljonen for commenting on the manuscript as well as the three anonymous peer-reviewers whose comments were very valuable and helped us to develop the paper.

Conflicts of Interest: The authors declare no conflict of interest.

\section{References}

1. Owens, S.; Cowell, R. Land and Limits: Interpreting Sustainability in the Planning Process; RTPI Library Series; Taylor \& Francis: Didcot, UK, 2011; ISBN 978-1-136-83483-7.

2. Agyeman, J. Sustainable Communities and the Challenge of Environmental Justice; NYU Press: New York, NY, USA, 2005; ISBN 978-0-8147-0711-1.

3. Agyeman, J.; Bullard, R.D.; Evans, B. Just Sustainabilities: Development in an Unequal World; Urban and Industrial Environments; MIT Press: Cambridge, MA, USA, 2003; ISBN 978-0-262-51131-5. 
4. Boone, C.G.; Buckley, G.L.; Grove, J.M.; Sister, C. Parks and People: An Environmental Justice Inquiry in Baltimore, Maryland. Ann. Assoc. Am. Geogr. 2009, 99, 767-787. [CrossRef]

5. Schlosberg, D. Defining Environmental Justice: Theories, Movements, and Nature; Oxford University Press: Oxford, UK, 2009; ISBN 978-0-19-956248-0.

6. Lind, E.A.; Tyler, T.R. The Social Psychology of Procedural Justice; Critical Issues in Social Justice; Springer: New York, NY, USA, 2013; ISBN 978-1-4899-2115-4.

7. Kangasoja, J. Retooling Planning-Towards Trading Zone Capabilities; Aalto University Publication Series Doctoral Dissertations; Aalto University: Espoo, Finland; Helsinki, Finland, 2017; ISBN 978-952-60-7732-1.

8. Harvey, D. Social Justice and the City; Geographies of Justice and Social Transformation Series; University of Georgia Press: Athens, GA, USA, 2010; ISBN 978-0-8203-3604-6.

9. Healey, P. Collaborative Planning: Shaping Places in Fragmented Societies; Planning, Environment, Cities; UBC Press: Vancouver, BC, Canada, 1997; ISBN 978-0-7748-0598-8.

10. Allmendinger, P. Towards a Post-Positivist Typology of Planning Theory. Plan. Theory 2002, 1, 77-99. [CrossRef]

11. Saarikoski, H. Naturalized Epistemology and Dilemmas of Planning Practice. J. Plan. Educ. Res. 2002, 22, 3-14. [CrossRef]

12. Rydin, Y. Re-Examining the Role of Knowledge Within Planning Theory. Plan. Theory 2007, 6, 52-68. [CrossRef]

13. Innes, J.E.; Booher, D.E. Collaborative rationality as a strategy for working with wicked problems. Landsc. Urban Plan. 2016, 154, 8-10. [CrossRef]

14. Forester, J. The Deliberative Practitioner: Encouraging Participatory Planning Processes; MIT Press: Cambridge, MA, USA, 1999; ISBN 978-0-262-56122-8.

15. Sager, T. Communicative Planning Theory; Rationality Versus Power; Avebury: Marlborough, UK, 1994; ISBN 978-1-85628-543-8.

16. Flyvbjerg, B. Rationality and Power: Democracy in Practice; Morality and Society Series; University of Chicago Press: Chicago, IL, USA, 1998; ISBN 978-0-226-25449-4.

17. Toledano, M. Dialogue, strategic communication, and ethical public relations: Lessons from Martin Buber's political activism. Public Relat. Rev. 2018, 44, 131-141. [CrossRef]

18. Land Use and Building Act 132/1999 National Legislation in Finland, English Translation. Available online: https:/ / www.finlex.fi/ fi/laki/kaannokset/1999/en19990132.pdf (accessed on 24 July 2018).

19. Puustinen, S.; Mäntysalo, R.; Hytönen, J.; Jarenko, K. The "deliberative bureaucrat": Deliberative democracy and institutional trust in the jurisdiction of the Finnish planner. Plan. Theory Pract. 2017, 18, 71-88. [CrossRef]

20. Rekola, A.; Paloniemi, R. Navigointia kestävän kaupunkisuunnittelun ristiaallokossa-Oikeudenmukaisuuden merkitys kaupunkisuunnittelijoille. [Navigating the riptides of sustainable urban planning-Meaning of environmental justice for the urban planners.] Under review in Janus. (In Finnish)

21. Vierikko, K.; Niemelä, J. Bottom-up thinking-Identifying socio-cultural values of ecosystem services in local blue-green infrastructure planning in Helsinki, Finland. Land Use Policy 2016, 50, 537-547. [CrossRef]

22. Paloniemi, R.; Niemelä, J.; Soininen, N.; Laatikainen, T.; Vierikko, K.; Rekola, A.; Viinikka, A.; Yli-Pelkonen, V.; Assmuth, T.; Kopperoinen, L.; et al. Environmental justice for the governance of aquatic environments. Local Environ. 2018, 23, 366-377. [CrossRef]

23. Hytönen, J. The problematic relationship of communicative planning theory and the Finnish legal culture. Plan. Theory 2014, 15, 223-238. [CrossRef]

24. Hunold, C.; Young, I.M. Justice, Democracy, and Hazardous Siting. Polit. Stud. 1998, 46, 82-95. [CrossRef]

25. Barth, M.; Michelsen, G. Learning for change: An educational contribution to sustainability science. Sustain. Sci. 2013, 8, 103-119. [CrossRef]

26. Vare, P.; Scott, W. Learning for a Change: Exploring the Relationship Between Education and Sustainable Development. J. Educ. Sustain. Dev. 2007, 1, 191-198. [CrossRef]

27. Wals, A.E.J.; Rodela, R. Social learning towards sustainability: Problematic, perspectives and promise. NJAS Wagening. J. Life Sci. 2014, 69, 1-3. [CrossRef]

28. Argyris, C.; Schön, D.A. Organizational Learning II: Theory, Method, and Practice; Addison-Wesley OD Series; Addison-Wesley Publishing Company: Boston, MA, USA, 1996; ISBN 978-0-201-62983-5.

29. Armitage, D.; Marschke, M.; Plummer, R. Adaptive co-management and the paradox of learning. Glob. Environ. Chang. 2008, 18, 86-98. [CrossRef] 
30. Barab, S.A.; Roth, W.-M. Curriculum-Based Ecosystems: Supporting Knowing From an Ecological Perspective. Educ. Res. 2006, 35, 3-13. [CrossRef]

31. Cunliffe, A.L. Republication of “On Becoming a Critically Reflexive Practitioner". J. Manag. Educ. 2016, 40, 747-768. [CrossRef]

32. Schön, D.A.; Rein, M. Frame Reflection: Toward the Resolution of Intractable Policy Controversies; Lexington Books: Lanham, MD, USA, 2002; ISBN 978-0-7391-0172-8.

33. Mezirow, J. Transformative Learning as Discourse. J. Transform. Educ. 2003, 1, 58-63. [CrossRef]

34. Weiss, C.H. Research for Policy's Sake: The Enlightenment Function of Social Research. Policy Anal. 1977, 3 , 531-545.

35. Rodela, R.; Cundill, G.; Wals, A.E.J. An analysis of the methodological underpinnings of social learning research in natural resource management. Ecol. Econ. 2012, 77, 16-26. [CrossRef]

36. Milkoreit, M.; Moore, M.-L.; Schoon, M.; Meek, C.L. Resilience scientists as change-makers-Growing the middle ground between science and advocacy? Environ. Sci. Policy 2015, 53, 87-95. [CrossRef]

37. Pohl, C.; Rist, S.; Zimmermann, A.; Fry, P.; Gurung, G.S.; Schneider, F.; Speranza, C.I.; Kiteme, B.; Boillat, S.; Serrano, E.; et al. Researchers' roles in knowledge co-production: Experience from sustainability research in Kenya, Switzerland, Bolivia and Nepal. Sci. Public Policy 2010, 37, 267-281. [CrossRef]

38. Clark, W.C.; Tomich, T.P.; van Noordwijk, M.; Guston, D.; Catacutan, D.; Dickson, N.M.; McNie, E. Boundary work for sustainable development: Natural resource management at the Consultative Group on International Agricultural Research (CGIAR). PNAS 2016, 113, 4615-4622. [CrossRef] [PubMed]

39. Schot, J.; Geels, F.W. Strategic niche management and sustainable innovation journeys: Theory, findings, research agenda, and policy. Technol. Anal. Strateg. Manag. 2008, 20, 537-554. [CrossRef]

40. Wittmayer, J.M.; Schäpke, N. Action, research and participation: Roles of researchers in sustainability transitions. Sustain. Sci. 2014, 9, 483-496. [CrossRef]

41. Aarrevaara, T.; Pulkkinen, K. Societal Interaction of Science in Strategic Research Council Funded Projects-Public Engagement Innovations for Horizon 2020. 2016. Available online: https:/ / pe2020.eu/wpcontent/uploads/2014/02/Soc-interaction-at-SRC_160916_valmis.pdf (accessed on 24 July 2018).

42. Flick, U. An Introduction to Qualitative Research; SAGE Publications: Newcastle upon Tyne, UK, 2014; ISBN 978-1-4462-9772-8.

43. Hart, P.; Taylor, M.; Robottom, I. Dilemmas of Participatory Enquiry: A case study of method-in-action. Assess. Eval. High. Educ. 1994, 19, 201-214. [CrossRef]

44. Alvesson, M.; Sköldberg, K. Reflexive Methodology: New Vistas for Qualitative Research; SAGE Publications: Newcastle upon Tyne, UK, 2017; ISBN 978-1-5264-2886-8.

45. Beltramo, J.L. Developing adaptive teaching practices through participation in cogenerative dialogues. Teach. Teach. Educ. 2017, 63, 326-337. [CrossRef]

46. Atweh, B.; Kemmis, S.; Weeks, P. Action Research in Practice: Partnership for Social Justice in Education; Taylor \& Francis: Didcot, UK, 2002; ISBN 978-1-134-69492-1.

47. Lewin, K. Action research and minority problems. J. Soc. Issues 1946, 2, 34-46. [CrossRef]

48. Burnes, B. Kurt Lewin and the Planned Approach to Change: A Re-appraisal. J. Manag. Stud. 2004, 41, 977-1002. [CrossRef]

49. Lewin, K. Group Decision and Social Change. In Readings in Social Psychology; Maccoby, E.E., Newcomb, T.M., Hartley, E.L., Eds.; Holt, Rinehart \& Winston: New York, NY, USA, 1958; pp. 197-211.

50. Greenwood, D.J.; Levin, M. Introduction to Action Research: Social Research for Social Change; SAGE Publications: Newcastle upon Tyne, UK, 2007; ISBN 978-1-4129-2597-6.

51. Argyris, C.; Schön, D.A. Participatory Action Research and Action Science Compared: A Commentary. Am. Behav. Sci. 1989, 32, 612-623. [CrossRef]

52. Glaser, B.G.; Strauss, A.L. The Discovery of Grounded Theory: Strategies for Qualitative Research; Observations: Chicago, IL, USA; Aldine, TX, USA, 1967; ISBN 978-0-202-30260-7.

53. Habermas, J. The Theory of Communicative Action; The Theory of Communicative Action; Beacon Press: Boston, MA, USA, 1984; ISBN 978-0-8070-1507-0.

54. Terry, P.R. Habermas and education: Knowledge, communication, discourse. Curric. Stud. 1997, 5, $269-279$. [CrossRef]

55. Arnstein, S.R. A Ladder of Citizen Participation. J. Am. Inst. Plan. 1969, 35, 216-224. [CrossRef] 
56. Schön, D.A. The Reflective Practitioner: How Professionals Think In Action; Basic Books: New York, NY, USA, 1984; ISBN 978-0-465-06878-4.

57. Puustinen, S. Suomalainen Kaavoittajaprofessio ja Suunnittelun Kommunikatiivinen Kaanne. Vuorovaikutuksen Liittyvat Ongelmat ja Mahdollisuudet Suurten Kaupunkien Kaavoittajien Nakokulmasta. [The Finnish Planning Profession and the Communicative Turn in Planning]. Doctoral Thesis, Helsinki University of Technology, Espoo, Finland, 2006.

58. Fraser, N. Social Justice in the Age of Identity Politics: Redistribution, Recognition, and Participation. In Culture and Economy after the Cultural Turn; SAGE Publications Ltd: London, UK, 1999; pp. 25-52.

59. Foucault, M. Discipline and Punish: The Birth of the Prison; Peregrine Books; Vintage Books: New York, NY, USA, 1977; ISBN 978-0-679-75255-4.

60. Bourdieu, P. The Logic of Practice; Polity Press: Cambridge, UK, 1990; ISBN 978-0-7456-0597-5.

61. Habermas, J. Knowledge and Human Interests; Polity Press: Cambridge, UK, 1987; ISBN 978-0-7456-0459-6.

62. Putnam, R.D. Bowling Alone: The Collapse and Revival of American Community; A Touchstone Book; Simon \& Schuster: New York, NY, USA, 2001; ISBN 978-0-7432-0304-3.

63. Hoffman, A.M. A Conceptualization of Trust in International Relations. Eur. J. Int. Relat. 2002, 8, 375-401. [CrossRef]

64. Foster, J. Sustainability, Higher Education and the Learning Society. Environ. Educ. Res. 2002, 8, 35-41. [CrossRef]

65. Argyris, C. Overcoming Organizational Defenses: Facilitating Organizational Learning; Allyn and Bacon: Boston, MA, USA, 1990; ISBN 978-0-205-12338-4.

66. Hoppe, R. Rethinking the science-policy nexus: From knowledge utilization and science technology studies to types of boundary arrangements. Poiesis Prax 2005, 199-215. [CrossRef]

(C) 2018 by the authors. Licensee MDPI, Basel, Switzerland. This article is an open access article distributed under the terms and conditions of the Creative Commons Attribution (CC BY) license (http:/ / creativecommons.org/licenses/by/4.0/). 